\title{
EDUCATION SATISFACTION OF MEDICAL AESTHETICS STUDENTS AT MEDICAL COLLEGE OF VARNA
}

\author{
Georgieva L. ${ }^{1}$, L. Tzvetkov ${ }^{2}$ \\ ${ }^{1}$ Department of Social Medicine and Healthcare Organization, \\ Medical University Prof. Dr. Paraskev Stoyanov, Varna, ${ }^{2}$ Medical College, Varna
}

\author{
Reviewed by: Assoc. Prof. St. Popova
}

\begin{abstract}
Research results on the satisfaction of students graduating with Medical Aesthetics, Wellness and Spa specialty from Medical College of Varna are presented. The complete assessment of the conducted training is „good". The theoretical training and the additional medical knowledge acquirement are assessed higher compared to the practical training. Insufficient satisfaction has been expressed from the time arrangement of the program, the lack of equipment for conducting practical training, and the scarcity of suitable handbooks. The detailed assessments and recommendations will serve for optimizing the program according to the expectations of the students.
\end{abstract}

Key words: satisfaction, students, education, medical aesthetics, medical college

\section{INTRODUCTION}

The perception of cosmetics is evolving through the ages from a beautifying tool to a tool for health improvement of the skin and its appendices (hair, nails), which gradually gets cosmetics close to medicine and results in differentiation of its two directions: decorative and medical cosmetics. Decorative cosmetics aims to achieve appearance attractiveness, making the defects of skin and its appendices less noticeable by the use of makeup tools. Based on the understanding that the appearance depends on the health status of the whole organism, cosmetics development requires to be put on a broad medical basis (4). Medical cosmetics aims to improve hygiene and appearance of skin and its appendices by the use of hygienic, protective and aesthetic tools (1). In contemporary society appearance care is not only a hygienic requirement, but also a necessity. Trends in customer demand show an increasing interest at cosmetic products and procedures. Cosmetic industry offers continuously new products, while dermatology prefers cosmetical minimalism. Recommending the so called "cosmetic diet" (simplified care - hygiene, sun protection, products and procedures according to the specific needs of particular skin), medicine attempts to protect the natural human aspiration to beauty from subordination to the beautiful packages of the cosmetic products and to the aggressive cosmetic advertisement. Medical cosmetics sets the problem to

Address for correspondence:

L. Georgieva, Dept. of Social Medicine and Healthcare Organization, Medical University Prof. Dr. Paraskev Stoyanov

55 Marin Drinov Str., 9002 Varna, Bulgaria

e-mail: lorahg@abv.bg achieve a harmony between health and beauty from the viewpoint of the commonly accepted criteria of aesthetics.

Based on the increasing necessity for putting cosmetics on a medical basis and the needs for education in medical cosmetics at academic level, a modular paid education in Medical Aesthetics has started at the Medical College of Varna for those graduated as: Nurse, Midwife, Doctor's Assistant, Assistant Pharmacist, Rehabilitation Therapist, Medical-Lab Worker, X-ray Lab-Worker, Health Inspector. In order to harmonize the specialty with the international theory, practice and terminology, the name has been changed to Medical Aesthetics, Wellness and Spa.

The term "wellness" has no exact Bulgarian translation which expresses its meaning in one word.

The World Health Organisation defined health as "a state of complete physical, mental and social well-being, and not merely the absence of disease or infirmity" (5). Mental health refers to an individual's emotional and psychological well-being. "Mental health" and "mental illness" are not opposites - the absence of a recognized mental disorder is not necessarily an indicator of sound mental health. One way to think about mental health is by looking at how effectively and successfully a person functions. Feeling capable and competent, being able to handle normal levels of stress, lead an independent life, and recover from difficult situations, are signs of mental health. A combination of physical, social and most importantly mental well-being is necessary to achieve overall health. Wellness is a view of health that emphasizes the state of the entire being and its ongoing development. There have been many terms used to define and describe wellness. According to the Medical Wellness Association these include optimal health, health promotion and total 
health. Optimal well-being requires the balancing of lifestyle and various dimensions of the whole person. These dimensions of health include physical, mental, emotional, environmental, spiritual and social components (3).

Wellness is generally used to mean a healthy balance of the mind, body and spirit that results in an overall feeling of well-being. All wellness strategies aim to achieving a state of physical and spiritual balance - strong body and positive psychological attitude through the right management of everyday activity. Wellness is a choice of lifestyle, subordinated to the holistic health approach. where since medieval times illnesses caused by iron deficiency were treated by drinking chalybeate (iron bearing) spring water.

In a narrow sense a "Spa center" should be considered only that one which offers healing procedures with water. However, everywhere water procedures are combined with additional ones and are conditionally partitioned into four zones: heat procedures, water procedures, massages and cosmetics, active relaxation.

Today's spa is a center for healing mind, body and spirit. Spa centers offer a wide variety of techniques for improv-

Table 1. Curriculum in Medical Aesthetics, Wellness and Spa.

\begin{tabular}{|c|c|c|c|c|c|}
\hline \multicolumn{2}{|l|}{ First module } & \multicolumn{2}{|l|}{ Second module } & \multicolumn{2}{|c|}{ Third module } \\
\hline Discipline & hours & Discipline & hours & Discipline & hours \\
\hline Dermatovenerology & 60 & Dermatovenerology & 30 & Dermatoallergology & 20 \\
\hline $\begin{array}{l}\text { Physiology and Biochemistry of } \\
\text { Skin }\end{array}$ & 30 & Physical Therapy & 30 & Endocrinology & 30 \\
\hline Introduction to Medical Aesthetics & 20 & Plastic and Aesthetic surgery & 30 & Nutrition and Dietetics & 15 \\
\hline Aesthetics and Health & 30 & Cosmetic Massage & 40 & Face Gymnastics & 20 \\
\hline $\begin{array}{l}\text { Introduction to Medical Cosmetic } \\
\text { Products }\end{array}$ & 15 & Reflective Massage & 40 & Medical Ecology & 15 \\
\hline $\begin{array}{l}\text { Information Systems and } \\
\text { Technologies }\end{array}$ & 30 & Face Gymnastics & 20 & $\begin{array}{l}\text { Basics of } \\
\text { Enterpreneurship }\end{array}$ & 15 \\
\hline Medical Informatics & 30 & $\begin{array}{l}\text { Technology of Medical } \\
\text { Cosmetic Products }\end{array}$ & 60 & $\begin{array}{c}\text { Marketing, Promotion and } \\
\text { Advertisement }\end{array}$ & 15 \\
\hline Communications in Healthcare & 30 & $\begin{array}{c}\text { Customer Care and Individual } \\
\text { Approach }\end{array}$ & 10 & $\begin{array}{l}\text { Management and } \\
\text { Organizational Behavior }\end{array}$ & 15 \\
\hline Psychology of Care & 30 & Application of Nature Factors & 10 & $\begin{array}{l}\text { Accounting and Taxation } \\
\text { Aspects }\end{array}$ & 15 \\
\hline $\begin{array}{l}\text { Wellness, Spa, Balneotherapy and } \\
\text { Thalassotherapy Center }\end{array}$ & 15 & $\begin{array}{c}\text { Chinese Medicine and } \\
\text { Ayurveda }\end{array}$ & 10 & $\begin{array}{c}\text { Responsibilities of } \\
\text { Wellness \& Spa managers }\end{array}$ & 5 \\
\hline \multirow[b]{2}{*}{$\begin{array}{l}\text { Individual work and } \\
\text { self-preparation }\end{array}$} & \multirow[b]{2}{*}{50} & \multirow[b]{2}{*}{$\begin{array}{l}\text { Aroma-, Colour-, Music-, } \\
\text { Kinesitherapy }\end{array}$} & \multirow[b]{2}{*}{10} & Quality Management & 15 \\
\hline & & & & $\begin{array}{l}\text { Individual work and } \\
\text { self-preparation }\end{array}$ & 30 \\
\hline Consultations & 60 & Consultations & 10 & Consultations & 30 \\
\hline Practice & 300 & Practice & 300 & Practice & 360 \\
\hline Total number of hours & 700 & Total number of hours & 600 & Total number of hours & 600 \\
\hline
\end{tabular}

"Wellness center" is defined as a center that offers procedures with beneficial action on the physical and psychical state (water, cosmetic, motional, relaxing therapy, etc.). There are some versions about the origin of the term "spa". The most popular explanation is that the word is an acronym of a Latin phrase "sanus per aquam" meaning "health through water". Another explanation is that the term may be derived from the Latin word "spagere" meaning "to scatter, sprinkle or moisten". It is also suggested that the term is derived from the name of the Belgian town of Spa, ing health, stress management, peace of mind and wellness. The International Spa Association (ISPA) has defined the "ten domains of spa": waters; food, diet and nutrition; movement, exercise and fitness; touch, massage and bodywork; mind/body/spirit; aesthetics, skin care, natural beauty agents; physical space, climatology, global ecology; social/cultural arts and values; management, marketing and operations; time, rhythm and cycles. Founded in 1991, ISPA is the professional organization of the spa industry, representing more than 3200 health and wellness facilities 
in 83 countries. ISPA advances the spa industry by providing educational and networking opportunities, promoting the value of the spa experience and speaking to foster professionalism and growth (2).

The settling name of such kind of centers is "Wellness and Spa". Despite of the popular perception of Wellness and Spa centers as offering modern procedures for active relaxation, most of them are essentially rehabilitation centers and have particular direction towards physiological functions of human organism.

The first education in the specialty of Medical Aesthetics, Wellness and Spa was conducted at the Medical College of Varna from 01.03.2007 to 31.07.2008. The disciplines included in the curriculum are presented in Table 1.

In the hours distribution has been considered the principle of theory and practice alternating and interdisciplinary connection realization. The major practical education form is work in small groups - up to three trained. Object of grading in the curricular practice are: professional skills, ability to assess customer needs, ability to make independent decisions, communication abilities.

\section{AIM}

The aim of the present study is to determine the satisfaction of the students graduating from the Medical Aesthetics, Wellness and Spa specialty at the Medical College of Varna.

\section{MATERIAL AND METHODS}

In the study are included all ten students gone through education in Medical Aesthetics, Wellness and Spa at the Medical College of Varna. A study tool is a specially developed inquiry card with 32 questions, directed towards the opinion of the students about the different elements of the conducted education. The satisfaction is studied according to the three-grade scale (fully satisfied, partially satisfied, unsatisfied) and as a grade (excellent, very good, good, satisfactory, poor). Suggestions have been asked for optimizing the organization and the contents of the curriculum, to serve for future changes, corresponding to the expectations of the students.

\section{RESULTS AND DISCUSSION}

The students gone through the education (females) have the following preliminary education structure: Nurse - 6, Doctor's Assistant - 1, Midwife - 1, Assistant Pharmacist - 1 and Medical Lab-Worker - 1. The work experience in the medical specialty is: from 1 to 10 years -6 , from 11 to 15 years - 2, over 30 years - 1, without work experience in the medical specialty - 1 student.

Motives for education in the Medical Aesthetics specialty are (the asked have given more than one answer): professional qualification improvement - 9, willingness for more medical knowledge -8 , willingness to develop own business - 7, curiosity - 3, more knowledge about medical equipment -2 , unwillingness to practice the medical specialty -1 , job as a cosmetic products representative -1 . Fully satisfied of the education as a whole are 6, partially satisfied are 4 students.

Fully satisfied of the theoretical preparation are 6, partially satisfied - 4 students. As reasons for insufficient satisfaction are pointed out: some non-modernized lectures, not good sequence in the lecture material, impossibility for lecture copying. Expected but not received knowledge is: cosmetic face treatment, permanent makeup and pedicure. As most beneficial theoretical disciplines are pointed out (the asked have given more than one answer): Dermatology (10), Physical Therapy (7), Communications in Healthcare (6), Marketing, Promotion and Advertisement (4), Technology of Medical Cosmetic Products (4), Wellness, Spa, Balneotherapy and Thalassotherapy Center (4), Medical Ecology (1) and Plastic Surgery (1). According to the aim of the developed program for extending the volume of medical knowledge of the practicing cosmeticians, the students' opinion has been asked for the expected and the presented medical information. Fully satisfied of the received medical information are 6, partially satisfied are 4 who have expected to receive more medical knowledge.

Full satisfaction of the acquired knowledge of cosmetic equipment is expressed by 5 students, partial - by the rest ones. The question about the expected knowledge, as well as about the correspondence between expected and received knowledge, has not been answered by 9 students, which illustrates the insufficient knowledge and use of modern cosmetic equipment. One student has pointed out as unsatisfactory the insufficient work with demonstration equipment.

Fully satisfied of the practical preparation are 4, partially satisfied - 6 students. As reasons for insufficient satisfaction are pointed out the lack of equipment in the college and insufficient engagement of the teachers of individual practical training of the students. The following practical disciplines are pointed out as most useful: all (4), face cosmetics (2) and massage (1); 3 students have not answered this question. Desired but not available practical disciplines are: spa-etiquette (2), mud- and wax-treatment (1), reflex therapy (1), manicure, pedicure and permanent makeup (1). Expectations of all students have been for more practical disciplines during education.

Of the whole educational organization fully satisfied are 3 students, partially - 6, one student is unsatisfied. The directed recommendation is for curricular program preparation without classes during the weekends.

The total grade for the educational course is: very good given by 3 students, good - by 6 , satisfactory - by 1 student. The grade for the theoretical preparation is: very good -4 , good - 6 . The practical preparation is graded as: excellent 1 , very good -2 , good -5 , satisfactory -2 . The grade for the organization of classes is: very good -4 , good -4 , satisfactory -1 , poor -1 . The equipment for the practical exercises 
is graded as very good by 3 students, as good by 6 and as satisfactory by 1 .

The theoretical materials used by the students for their independent preparation are (the asked have given more than one answer): lectures (10), materials from seminar classes (5), textbooks (5), other information - from Internet and journals. Literature at the Medical University library has been searched by one student only. The general opinion of the students is about the lack of suitable handbooks for theoretical preparations in medical cosmetics.

The question "With what has the education contributed to your development as a professional?" has been answered by all students similarly: improved qualification and increased professional self-confidence.

ine students would recommend the Medical Aesthetics education to their colleagues. The only negative answer is motivated by the lack of validated duty characteristic for medical cosmetician.

The students recommend: better organization of lectures and practical training; provision of equipment for practical training at Medical College; expressed is a willingness to get a higher educational degree which to separate the graduated from the other cosmeticians.

\section{CONCLUSIONS}

- The major motives for education in Medical Aesthetics are: to increase the professional qualification as a cosmetician, to get more medical knowledge, and willingness to develop own business. The motivation, associated with improving the professional competence and expanding its medical explanation, shows the rightness of the introduction of the education at Medical College. The motivation, associated with the intention to develop own cosmetic business, directs towards the need for a deeper presentation of managerial and economic disciplines in the education.

- The satisfaction of the received practical preparation is weaker compared to that of the theoretical one, which shows a need for individual practical training.
- Considering the lacking knowledge of the students about cosmetic equipment, it is necessary to deliver more time for teaching the structure and rules of operation with modern equipment and consumptives.

- The prevailing "good" grades for the conducted education show that the optimal organization of the curriculum has not been achieved, and major problems are: class time distribution and lack of own equipment for practical training.

- The theoretical preparation of students has been achieved mainly through the delivered lecture material. The lack of literature in medical cosmetics at the Medical University library, as well as the impossibility to get the lectures on a hard copy or electronic format, impede the students and put a need of developing proper educational materials.

- The students wish to get a higher educational degree upon finishing their education, which to distinguish them from the rest of the practicing cosmeticians and thus to give them a greater chance for a professional establishment.

- The analysis of the results in the present study shows that the education at the Medical College is considered a good opportunity to get a professional qualification in medical cosmetics, and the detailed grades and the recommendations will serve for optimizing the program according to the expectations of the educated.

\section{REFERENCES}

1. Durmishev A. (ed.) Dermatology and Venerology. Sofia: MF, 2000. /in Bulgarian/

2. International SPA Association (http://spas.about.com/gi/dynamic/offsite.htm?site=http://www.experienceispa.com)

3. Medical Wellness Association. Definition of Wellness. Medical Wellness Journal 2008; 5(2):3.

4. Peng QX, Wang X, Zhao JY. The rise and prospects of medical aesthetics. Social Science \& Medicine 1995; 41(8):1197-1201.

5. WHO. Constitution. Geneva: WHO, 1946. 